\title{
In Silico Study of Andrographolide as Protease Inhibitors for Antimalarial Drug Discovery
}

\author{
Sandra Megantara ${ }^{1,2^{*}}$, Jutti Levita ${ }^{2}$, Slamet Ibrahim $^{1}$ \\ ${ }^{I}$ School of Pharmacy, Bandung Institute of Technology, Jl Ganesha 10 Bandung, Indonesia. \\ ${ }^{2}$ Faculty of Pharmacy, Universitas Padjadjaran, Jl Raya Bandung Sumedang Km 21,5, Indonesia.
}

Received: 5 November 2014 / Accepted: 30 November 2014

\begin{abstract}
:
Malaria parasite encodes several homologues of aspartic proteases such as plasmepsin I, II and IV which are responsible for degradation of host erythrocyte hemoglobin inside the vacuole of parasite food. Hence plasmepsins are novel targets for antimalarial drug discovery. Previous study concluded that Andrographis paniculata herbs extract has been proven to exert antimalarial activity. However, the molecular mechanism of this activity was not described. The objectives of this paper were to investigate the interaction between andrographolide, a major constituent of Andrographis paniculata with the ligand binding domain of plasmepsin I, II and IV, to find the most favorable binding site as well as to predict the binding mode. Pepstatin, a protease inhibitor, was used as standard. Docking studies showed that pepstatin gave better binding interactions to plasmepsin I, II and IV with binding affinity and inhibition constant of $\mathrm{E}_{\mathrm{i}}=-10.3 \mathrm{kcal} / \mathrm{mol} ; \mathrm{K}_{\mathrm{i}}=0.02 \mu \mathrm{M}$ (plasmepsin I), $\mathrm{E}_{\mathrm{i}}=-8.9 \mathrm{kcal} / \mathrm{mol} ; \mathrm{K}_{\mathrm{i}}=0.3 \mu \mathrm{M}$ (plasmepsin II), $\mathrm{E}_{\mathrm{i}}=-9.3 \mathrm{kcal} / \mathrm{mol} ; \mathrm{K}_{\mathrm{i}}=0.15 \mu \mathrm{M}$ (plasmepsin IV), respectively, while andrographolide showed $\mathrm{E}_{\mathrm{i}}=-9.8 \mathrm{kcal} / \mathrm{mol} ; \mathrm{K}_{\mathrm{i}}=0.07 \mu \mathrm{M}$ (plasmepsin I), $\mathrm{E}_{\mathrm{i}}=-8.7 \mathrm{kcal} / \mathrm{mol} ; \mathrm{K}_{\mathrm{i}}=0.42 \mu \mathrm{M}$ (plasmepsin II), $\mathrm{E}_{\mathrm{i}}=-8.8$ $\mathrm{kcal} / \mathrm{mol} ; \mathrm{K}_{\mathrm{i}}=0.35 \mu \mathrm{M}$ (plasmepsin IV). According to the result, it was concluded that andrographolide could be developed as protease inhibitor for antimalarial drug.
\end{abstract}

Key words: Antimalarial, andrographolide, plasmepsin, protease inhibitor

\section{Introduction}

Hemoglobin metabolism is one of the key metabolic processes for the survival of the parasite in human blood. There are some proteases enzyme involved in the degradation of hemoglobin in the parasite food vacuole. Plasmepsin is an aspartic protease enzyme of the species P. falciparum that responsible for the initial cleavage of hemoglobin and is then followed by other protease enzymes [1]. Therefore, plasmepsin can be served as new targets for antimalarial drug discovery [2].

$P$. falciparum genome sequencing project has identified ten types of protein aspartate protease, where three of them are plasmepsin I, II and IV in charge in the early stages of hemoglobin degradation [3]. Recent studies have shown that effective drugs must be able to interact on more than one type of plasmepsin, this is due to the possibility of parasites can still survive if only one type of plasmepsin are inhibited, and also to avoid drug resistance in malaria treatment [4].

Plasmepsin is an aspartic protease enzyme in which the catalytic of the enzyme contains two aspartic acid residues [5]. Both of these aspartic acid residues act respectively as proton donors and acceptors, as well as a catalyst for the hydrolysis of peptide bonds in proteins [6]. Hemoglobin degradation process begins with the termination of phenylalanine 33 (Phe33) and leucine 34 (Leu34) in the $\alpha$-globin chains in hemoglobin [7].

Previous studies concluded that the extract of Andrographis paniculata shown to have activity as an antimalarial, but studies of other active compounds and molecular mechanism of action is not described $[8,9,10$, $11]$.

The main component of Andrographis paniculata is diterpenoid compound, named andrographolide [12]. In this study we determined the interaction and affinity of andrographolide against plasmepsin I, II and IV.

\section{Experimental}

Hardware and software

Docking calculations were carried out on branded Sony Vaio PC Linux Ubuntu 14.04 LTS as the operating system, with Intel $2.30 \mathrm{GHz}$ Core i5 and 4 GB memory hardware. The softwares used for docking preparation were SPORES, PLANTS 1.2, Open Babel 2.3.2 and python script from Autodock Tools. Meanwhile, PyMOL and AutoDock Vina 1.1 were used for RMSD calculation and binding algorithms. Virtual analysis of docking site was used by AutoDock Tools 1.5.6 and PoseView to generated two-dimensional diagrams of docking poses. 


\section{Material and methods}

The subjected aspartic protease receptors in this study was plasmepsin I, II, and IV (Fig.1). The structures of those receptors were obtained in pdb files from the protein data bank (www.pdb.org). The receptors code for plasmepsin I, II, and IV were 3QS1, 1SME, 1LS5 respectively. Each of receptors had been docked with pepstatin as native ligand, which has been known as aspartic protease inhibitor.
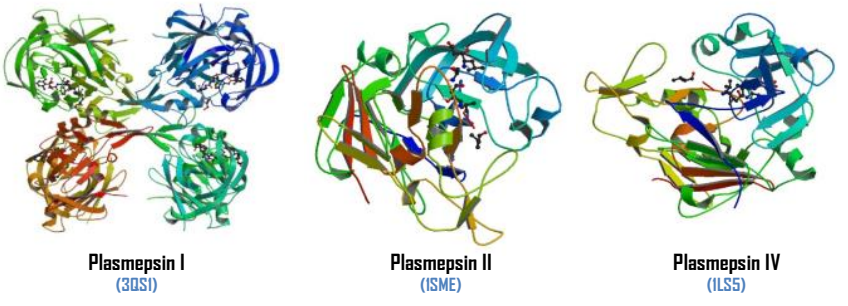

Figure 1. Crystal structure of Plasmepsin I, II and IV.

In preparation step, separation of native ligand for each receptor was carried out by using Structure Protonation and Recognition System (SPORES) software. SPORES was employed to split the pdb file to protein and ligands using the splitpdb module. The protein was recognized, protonated and stored as protein.mol2, while the reference ligand was also recognized, protonated and stored as ligand_ref.mol2. The binding site searched automatically using bind module of PLANTS 1.2 with radius distance of $5 \AA$ from the coordinates of the location where the native ligand was located in the reference crystal structure. Python script from Autodock Tools together with Open Babel 2.3.2 was also used to prepare the receptor and ligand to be docked using Autodock Vina by changing mol2 to pdbqt file extension.

Validation of docking protocols was carried out by redocking native ligand to receptor. The RMSD values calculations were performed using rms_cur module in PyMol. This process was repeated 100 times for each protein pdb files.

The docking process was performed to pepstatin as reference ligand (Figure 2), and andrographolide as test compound (Figure 3). This process was iterated 100 times to each protein.<smiles>CC(C)CC(=O)N[C@H](C(=O)N[C@H](C(=O)N[C@@H](CC(C)C)C(O)CC(=O)N[C@@H](C)C(=O)N[C@H](CC(C)C)[C@@H](O)CC(=O)O)C(C)C)C(C)C</smiles>

Figure 2. Pepstatin, an aspartic protease inhibitor.

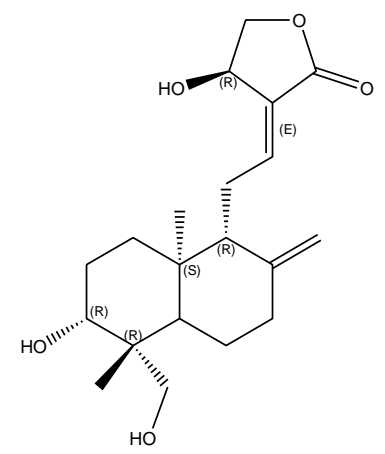

Figure 3. 2D structure of andrographolide.

\section{Results and Discussion}

The internal validation was aimed to examine whether the docking protocols can reproduce the pose of the co-crystal ligand [13]. The objective function used in the internal validation was the root mean square distance (RMSD) value between the heavy atoms of the docked pose and the crystal structure pose. The protocol is acceptable if the RMSD value is less than 2.0 [13]. The best RMSD value of 100 repetitions were $1.238 \AA, 1.684$ $\AA$ and $0.801 \AA$ for $3 \mathrm{QS} 1,1 \mathrm{SME}, 1 \mathrm{LS} 5$ respectively. By dividing the result of RMSD values from redocking process for each crystal structures (Fig. 4), it can be concluded that the docking protocols were valid.

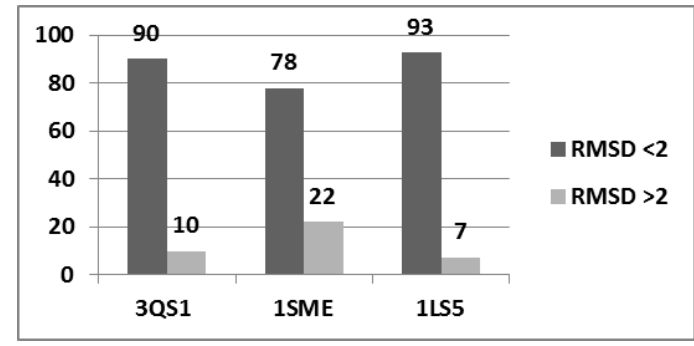

Figure 4. RMSD values larger and smaller than 2

The molecular docking results of reference ligand and test compounds are presented in Table 1. Pepstatin showed better binding interactions to plasmepsin I, II and IV than andrographolide, while andrographolide was potentially active as aspartic protease inhibitor (Table 1).

Table 1. Docking score results

\begin{tabular}{lrccc}
\hline \multirow{2}{*}{ Receptor } & \multicolumn{2}{c}{ Pepstatin } & \multicolumn{2}{c}{ Andrographolide } \\
& $\mathrm{E}_{\mathrm{i}}$ & $\mathrm{K}_{\mathrm{i}}$ & $\mathrm{E}_{\mathrm{i}}$ & $\mathrm{K}_{\mathrm{i}}$ \\
\hline Plasmepsin I & -10.3 & 0.02 & -9.8 & 0.07 \\
Plasmepsin II & -8.9 & 0.30 & -8.7 & 0.42 \\
Plasmepsin IV & -9.3 & 0.15 & -8.8 & 0.35 \\
\hline
\end{tabular}

$\mathrm{E}_{\mathrm{i}}=$ Binding affinity $(\mathrm{kcal} / \mathrm{mol})$

$\mathrm{K}_{\mathrm{i}}=$ Inhibition constant $(\mu \mathrm{M})$

The binding poses of andrographolide based on the best docking result with plasmepsin I, II and IV ware presented in two-dimensional diagram (Figure 5, 6 and 7). 


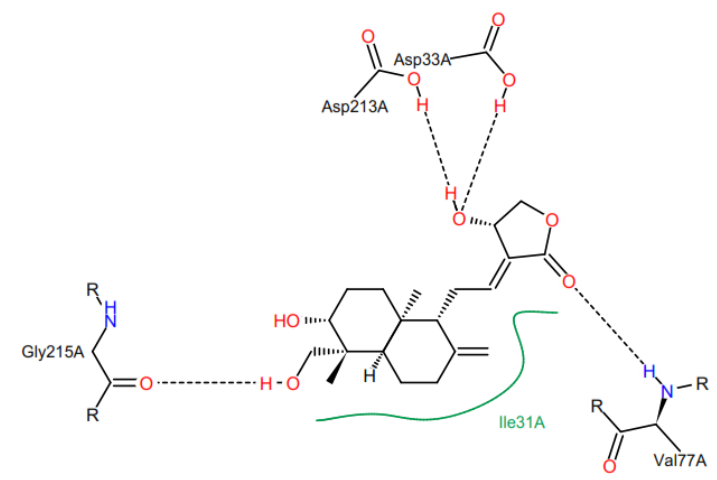

Figure 5. Interaction of andrographolide in the binding pocket of plasmepsin I.

Hydrogen bonds was formed with side chain of Gly215, Asp213, Asp33 and Val77 (Figure 5) where as hydrophobic interaction with side chain of Ile31. Two important aspartic acid residues in the binding pocket of plasmepsin I [14] were bound by hydroxyl group located at $\mathrm{C}-14$ in the lactone ring of andrographolide.

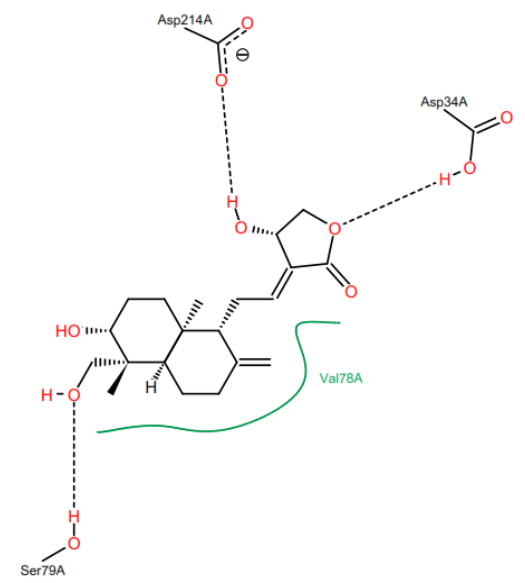

Figure 6. Interaction of andrographolide in the binding pocket of plasmepsin II.

Andrographolide forms hydrogen bonds with side chain of Ser79, Asp214, and Asp34 (Figure 6). Hydrophobic interaction was formed with side chain of Val78. In this pose, two important aspartic acid residues in the binding pocket of plasmepsin II [7], was bound by hydroxyl group located at C-14 and oxygen in the lactone ring of andrographolide.

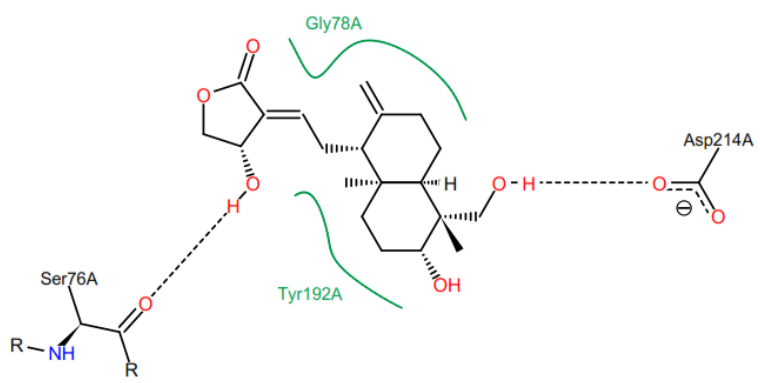

Figure 7. Interaction of andrographolide in the binding pocket of plasmepsin IV.
Andrographolide forms hydrogen bonds with side chain of Ser76 and Asp214 (Figure 7). Hydrophobic interaction was build with side chain of Gly78 and Tyr192. In this pose, just one important aspartic acid residues in the binding pocket of plasmepsin IV [15] was bound by hydroxyl group located at C-19 of andrographolide.

Based on three docking poses of andrographolide with plasmepsin I, II and IV, it can be concluded that there are three pharmacophores of andrographolide which are hydroxyl group located at C-14, C-19, and oxigen atom in the lactone ring (Fig. 8).

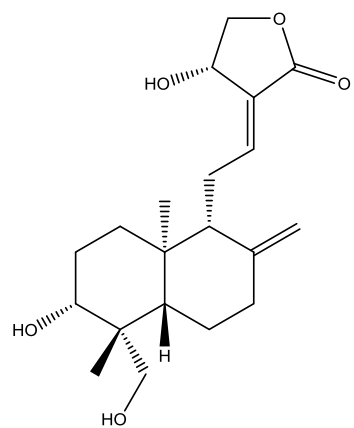

Figure 8. Pharmacophores of andrographolide which can interact with important aspartic acid residues of Plasmepsin I, II and IV.

These pharmacophores of andrographolide are exactly the same as previous work concluded by Levita [16] on cyclooxygenase enzyme and NF-kappaB for antiinflammatory drug discovery [16]. These moieties should be kept unmodified to maintain its biological activity.

\section{Conclusions}

Andrographolide could be developed as protease inhibitor for antimalarial drug, where structural modifications can be conducted to improve its binding affinity by keeping the pharmacophores.

\section{References}

[1] S.E. Francis, D.J. Sullivan, and D.E. Goldberg, Hemoglobin metabolism in the malaria parasite Plasmodium falciparum. Annu Rev Microbiol, 51, 97-123, receptor mutagenesis studies, J. Med. Chem., 54(23), 2011, 8136-8147.

[2] P.J. Rosenthal, Antimalarial drug discovery: old and new approaches. J Exp Biol, 206, 2003, 3735-3744.

[3] G.H. Coombs, D.E. Goldberg, M. Klemba, C. Berry, J. Kay, and J.C. Mottram, Aspartic proteases of Plasmodium falciparum and other parasitic protozoa as drug targets. Trends Parasitol, 17, 2001, 532-537.

[4] J. Liu, I.Y. Gluzman, M.E. Drew, and D.E. Goldberg, The role of Plasmodium falciparum food vacuole plasmepsins. $J$ Biol Chem, 280, 2005, 1432-1437.

[5] C. Berry, M.J. Humphreys, P. Matharu, R. Granger, P. Horrocks, R.P. Moon, U. Certa, R.G. Ridley, D. Bur, and J. Kay, A distinct member of the aspartic proteinase gene 
family from the human malaria parasite Plasmodium falciparum. FEBS Lett, 447, 1999, 149-154.

[6] D.R. Davies, The structure and function of the aspartic proteinases. Annu Rev Biophys Biophys Chem, 19, 1990, 189215.

[7] A.M. Silva, A.Y. Lee, S.V. Gulnik, P. Maier, J. Collins, T.N. Bhat, P.J. Collins, R.E. Cachau, K.E. Luker, I.Y. Gluzman, S.E. Francis, A. Oksman, D.E. Goldberg, and J.W. Erickson, Structure and inhibition of plasmepsin II, a hemoglobindegrading enzyme from Plasmodium falciparum. Proc Natl Acad Sci US A, 93, 1996, 10034-10039.

[8] K. Mishra, A.P. Dash, and N. Dey, Andrographolide: A Novel Antimalarial Diterpene Lactone Compound from Andrographis paniculata and Its Interaction with Curcumin and Artesunate. J Trop Med, 2011, 579518.

[9] K. Mishra, A.P. Dash, B.K. Swain, and N. Dey, Anti-malarial activities of Andrographis paniculata and Hedyotis corymbosa extracts and their combination with curcumin. Malar J, 8, 2009, 26.

[10] N.A.R.N. Najib, T. Furuta, S. Kojima, K. Takane, and M. Ali Mohd, Antimalarial activity of extracts of Malaysian medicinal plants. J Ethnopharmacol, 64, 1999, 249-254.

[11] U. Zein, L.E. Fitri, and A. Saragih, Comparative study of antimalarial effect of sambiloto (Andrographis paniculata) extract, chloroquine and artemisinin and their combination against plasmodium falciparum in-vitro. Acta Med Indones, 45, 2013, 38-43.

[12] T. Fujita, R. Fujitani, Y. Takeda, Y. Takaishi, T. Yamada, M. Kido, and I. Miura, On the diterpenoids of Andrographis paniculata: X-ray crystallographic analysis of andrographolide and structure determination of new minor diterpenoids. Chem. Pham. Bull, 32, 1984, 2117-2125.

[13] G. Marcou, D. Rognan, Optimizing fragment and scaffold docking by use of molecular interaction fingerprints. $J$ Chem Inf Model., 47, 2007, 195.

[14] P. Bhaumik, Y. Horimoto, H. Xiao, T. Miura, K. Hidaka, Y. Kiso, A. Wlodawer, R.Y. Yada, and A. Gustchina, Crystal structures of the free and inhibited forms of plasmepsin I (PMI) from Plasmodium falciparum. J Struct Biol, 175, 2011, 73-84.

[15] O.A. Asojo, S.V. Gulnik, E. Afonina, B. Yu, J.A. Ellman, T.S. Haque, and A.M. Silva, Novel uncomplexed and complexed structures of plasmepsin II, an aspartic protease from Plasmodium falciparum. $J$ Mol Biol, 327, 2003, 173181.

[16] J. Levita, Studi In Silico dan In Vitro Aktifitas Anti-Inflamasi Andrografolid serta Uji Biodistribusi Andrografolid dalam Mencit. 2001. Disertasi: ITB (unpublished). 